\title{
Social and behavioural aspects of venereal disease
}

\author{
VERA STARCK-ROMANUS \\ Gothenburg, Sweden
}

Socio-medical and psychiatric investigations of groups of V.D. patients have been carried out in several countries including Sweden and Denmark.

I will discuss mainly Swedish and Danish results, so that my conclusions may be only partly true for other countries.

As well as the research carried out in Uppsala by Juhlin (1968), thorough investigations of gonorrhoea in young people have been made by Gustavsson (1971) in Stockholm and by Ekstrøm $(1970,1972)$ in Copenhagen.

They found that their V.D. patients, more often than the controls, had a poor social background, bad education, and unskilled occupations, and showed signs of social maladjustment, such as juvenile delinquency, alcohol, or drug problems, and psychiatric disease. They started their sexual life young and had more partners. They had some sex education, but were unable to utilize their knowledge of contraception. (One third of the Danish girls between the ages of 13 and 19 years had been or were pregnant). Their knowledge of venereal diseases was poor.

How valid are these findings for V.D. patients in general?

The author has had experience in an out-patient department for skin and venereal diseases, in a contraception clinic, and in the field of sex education, and has paid short visits to England and last year a longer one to the U.S.A.

The question of how valid these findings are is an important one. There is a tendency to turn the reasoning upside down and to think that, since gonorrhoea is more common in people with a promiscuous way of life and with certain negative characteristics and a poor social background, everyone who has a venereal infection is that kind of person and has an equally bad background.

If this were a widespread view in society, there would be a risk of adopting a deprecatory attitude towards V.D. patients in general. They might perhaps be treated with contempt by medical personnel, and the community might provide only small resources for their medical care.

But certain facts indicate that the quoted findings are not valid for all V.D. patients.

(1) The age group studied in Stockholm was below 25 years and in Copenhagen below 20, corresponding to two-thirds and one-third, respectively, of all gonorrhoea cases reported in those cities at that time. Consequently there are many V.D. patients of other ages to whom these results cannot be directly applied.

(2) The studies were made in big cities. The behaviour pattern of rural patients may differ very much from that of urban ones. This view is confirmed by the study in Uppsala, where the patients had the same occupations as the other inhabitants of this relatively small town.

(3) Even the young patients in the big cities did not uniformly show these personality characteristics. In the Danish study, for example, 50 per cent. of the girls were infected by their regular consorts in a relationship described by themselves as a stable one.

(4) The investigation in Stockholm (and the main part of that in Copenhagen) was based on patients treated at special clinics, free of charge. In Copenhagen and in Stockholm 10 per cent. of all V.D. cases, and in other Swedish cities, e.g. Uppsala, 20 per cent., are reported by private practitioners. In addition, an unknown number of patients are treated for gonorrhoea without being reported at all, and some even without proper diagnosis. It might be mentioned that in the U.S.A. 80 per cent. of V.D. patients are treated by private physicians, and that only about one-tenth of them are reported.

According to some Swedish venereologists, most of their private patients correspond to the normal population.

Thus an opinion of venereal patients in general cannot be based on studies of young people in big cities, treated at special V.D. clinics.

Moreover, the publications quoted base their 
conclusions on conditions prevailing in the years 1964, 1965, and 1966. Since then gonorrhoea has become still more common and is now probably more widely spread in all strata of the population.

\section{Types of V.D. patients}

I. The first group consists of the young patients already mentioned with multiple problems. Their gonococcal infection is only one symptom among other signs of social maladjustment. This is probably the largest group of V.D. patients, at least in big cities. But one has no right to presume that everyone consulting a V.D. clinic belongs to this multipleproblem group, with all their negative characteristics. They, probably more often than others, have repeated infections and form a reservoir of infection which spreads rapidly within the group and occasionally to other members of society. It may be necessary to treat them immediately for suspected gonorrhoea without waiting for the diagnosis, because otherwise the patients may infect others or perhaps never return for treatment. This prophylactic treatment saves time, but to give proper care to the multiple-problem case time as well as interest is essential. It is true that the venereologist cannot give all the necessary psychotherapy and social rehabilitation, but it is very important that contact with the V.D. clinic should provide a positive experience for the patient. If we are in a hurry and show disapproval, we shall endanger our future relationship and strengthen the patient's negative attitude towards society. Attempts at rehabilitation later on will be more difficult, if one loses time and forfeits the confidence of the patient. Ekstrøm (1972) emphasized that the doctor does not talk enough with young patients, who badly need to discuss their problems.

II. The second group consists of young patients who are sexually promiscuous, but otherwise not maladjusted. In dealing with young people of this type it is very important to establish a good relationship with the patient, so that a later development towards social maladjustment may be prevented.

\section{AN EXAMPLE}

A 13-year-old girl, at one period of her life, had had several sexual contacts. Because of gonorrhoea she went to a V.D. clinic, which was of the 'mass-production' type. The doctor reproached her for being too young ('The doctor scolded me ...'), and she failed to return for follow-up, but after repeated summonses at last reluctantly returned. The same thing was repeated again and again, and finally she was fetched by the police, according to the Swedish law. She was brought by them to a small clinic, where there was time to talk to her in a friendly way, and only then, 9 months after her first contact with the V.D. authorities, was a psychological and social investigation performed. Now the girl is cooperative; her relations with her mother have improved, and she is grateful for having been treated sympathetically.

III. The third group contains patients who have normal stable personalities and belong to all professions and social positions. In this group we find the type of V.D. patient who is married or lives in a stable relationship, but who occasionally has other sex contacts. The patient will be infected in this way and may then infect the regular partner. These people feel, like most others, that a sexual relationship is quite different from other human relationships. In marital or other long-lasting relationships fidelity is an unexpressed presumption, and only monogamy is officially accepted.

To differentiate between these various types of patients we need time; the doctor as well as the social worker should interview the patients in order to form an opinion of their personality.

Psychological problems will arise for everyone infected by an extramarital contact. The patient will try to conceal the infidelity, but the infection brings about the risk of discovery.

A lingering sign of the male domination of society is shown by the fact that a male doctor will help a male patient to conceal an extramarital infection from his wife. In different ways they try to get the wife to visit a doctor, and the doctor endeavours to give her penicillin without revealing why. The assumption behind this is that the husband will not only get scolding and reproaches, but will be divorced by his wife if she learns of his infidelity. The serious social and financial consequences of divorce are thought to justify keeping the wife in ignorance and deciding that the marriage is to be protected-without letting her take part in this decision!

All V.D. patients are not promiscuous. This is shown by the fact that many are infected only once. A study in Stockholm in 1963 showed that 90 per cent. of the male and 85 per cent. of the female patients were infected only once that year (Gästrin and Kallings, 1964).

Recent studies in Stockholm and in Uppsala confirm this finding. In Stockholm (Karolinska Sjukhuset) in 1968, 55 per cent. of the males with gonorrhoea and 70 per cent. of the females had never had gonorrhoea before (Molin, 1970). In Uppsala in 1969, in different groups of male gonorrhoea patients, 94, 71, 62, 84 per cent. had never been infected with gonorrhoea before; the corresponding 
figures in females were $94,87,75$, and 96 per cent. (Wallin, 1971).

The faithful, innocently infected patient will experience a crisis of confidence in the relationship. The infection may bring about a confirmation of something that was suspected but not quite believed.

This stable group may be the smallest, but such patients are still numerous enough; all of us meet them often. For them there is no need of treatment before diagnosis. Many of them want to know definitely whether they are infected or not. A person who suspects a venereal disease is entitled to have the diagnosis confirmed or excluded before asking a possible contact to be examined.

We know that a certain number of patients cannot be diagnosed at the first visit, but most will be diagnosed in one of the first three examinations.

Moreover, 50 to 65 per cent. of all who attend a V.D. clinic in Sweden because of suspicion of V.D. do not have any such infection.

If everyone were treated at once on the assumption that 'V.D. patients are unreliable and will spread the infection', penicillin would be given unnecessarily to two or three times as many as are actually infected.

All these examples show that the venereologist needs time for the patient, a good education in behavioural sciences with an understanding of the problems of fidelity and infidelity, of monogamy and polygamy, and a thorough knowledge of human nature.

\section{Attitudes towards venereal diseases}

In society the attitude to venereal diseases is censorious compared with that to other infections, because of our rules concerning sexual behaviour, but promiscuity seems to be regarded as delinquency in girls, but not in boys.

The clinics for the treatment of V.D. are less attractive and often less well equipped than those for other diseases, and medical personnel too often meet the V.D. patient with distaste and prejudice. This is true of all specialties, not only of venereology, and regrettably it still happens that a doctor may call the patient a whore or tart.

In the patients themselves there is a wide range of reactions, from regarding the disease a mere trifle to a strong sense of shame and a severe emotional shock, and for this reason the attitudes of doctors and nurses in this specialty are very important. Even if some negative characteristics are found more often in V.D. patients, one must take care not to regard every one of them as identical with the 'statistically typical' patient.

\section{Desirable improvements}

How should the remaining prejudice be overcome? There are many different recommendations. Certain tolerant people think we should look upon V.D. as on 'any other disease'. According to this opinion, one should disregard the method of transmission and treat the subject as part of health education and not as part of sex information. My own opinion is that in medical practice the venereal diseases ought to be placed on a level with other diseases, but that to disregard the way of transmission is unrealistic. One cannot shut one's eyes to the fact that the infection is usually transmitted by sexual contact and so for most people has a special implication setting it apart from all other infections.

Another recommendation is to eliminate everything that makes people reluctant to visit the V.D. clinic. If there is an unfriendly atmosphere at a clinic, this will be generally known, and patients will postpone their visits as long as possible. Some are afraid of the examinations and even of being given injections. If they were told that treatment is available in tablet form, more might be willing to come.

\section{Summary}

We must require from the authorities the facilities and staff to maintain a satisfactory medical standard. Suitable premises and enough time for each patient are needed. We must object to medical care of an overcrowded, large-scale, 'mass-production' type. If a disease is a common one that is no reason to treat it less well than more unusual ones.

The education of physicians must include psychology to enable them to deal with emotional problems. Other personnel must also be given suitable education.

\section{Addendum on V.D. information in Sweden}

This has been compulsory in schools since 1956 . In spite of that the incidence of gonorrhoea has increased. Last year in June the Swedish Association for Sex Education arranged a campaign against gonorrhoea and recommended the use of rubber condoms. The campaign used big posters with a simple text easy to understand by people with poor education, and made in a humourous style. Since that campaign there has been a decrease in the incidence of gonorrhoea in Sweden. Instead of the usual increase of 4,000 cases/year in the last few years, in 1971 we had a decrease of 1,000 cases. There might be many factors behind this, but it is possible that the posters have, by portraying a tolerant 
attitude without moralizing, made people more willing to accept the information offered.

\section{References}

EkstrøM, K. (1970) Brit. F. vener. Dis., 46, 93

(1972) 'Gonorrhoe hos Unge'. Thesis (Summary in English). Munksgaard, Copenhagen

Gästrin, B., and Kallings, L. O. (1964) Acta derm.venereol. (Stockh.), 44, 286

Gustavsson, N. (1971) Läkartidningen, 68, 4280

JuHLIN, L. (1968) Acta derm.-venereol. (Stockh.), 48, 75,82

Molin, L. (1970) Social-med. Tidskr., 47, 87

WALLIN, J. (1971) Läkartidningen, 68, 199

\section{Aspects sociaux et de comportement des} maladies vénériennes

\section{SOMMAIRE}

Nous devons exiger des autorités équipement et personnel pour maintenir un niveau médical satisfaisant. Nous avons besoin de locaux appropriés et d'assez de temps à consacrer à chaque malade. Nous devons nous opposer à une activité médicale s'exerçant sur un nombre de malades excessif, à large échelle, du type 'production de masse'. Si une maladie est fréquente, ce n'est pas une raison pour la traiter moins bien que celles qui sont plus rares.

La formation des médecins doit comprendre la psychologie, pour leur permettre d'affronter les problèmes émotionnels. Le reste du personnel doit aussi recevoir une. éducation appropriée. 